\title{
Self-reported summarizing and paraphrasing difficulties in L2 writing contexts: Some pedagogical interventions
}

\author{
Eden Regala-Flores* and Michelle Lopez \\ Department of English and Applied Linguistics, De La Salle University, 2401 Taft Ave., Malate, 1004, \\ Manila, the Philippines
}

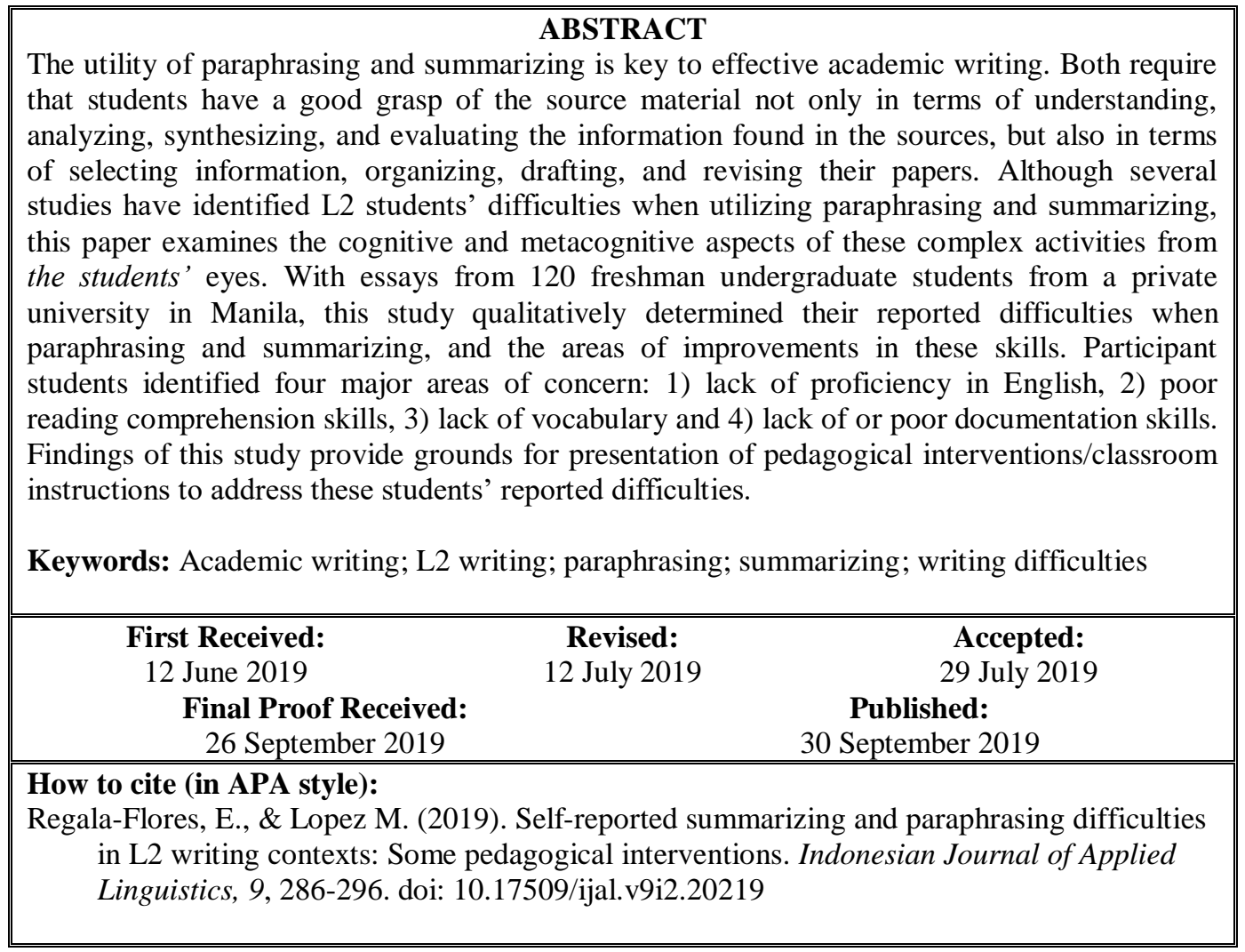

\section{INTRODUCTION}

One of the daunting challenges L2 students face in their college academic writing is successfully incorporating source information into their own writing. This is so because reading various sources to develop their own papers requires both knowledge telling and knowledge transforming (Bereiter \& Scardamalia, 1987). The former is a demonstration of their comprehension or understanding of what they read while the latter is their appropriation or use of the source information in their own writing (Hirvela \& Du, 2013).

Acquisition and mastery of both knowledge are widely accepted as cognitively demanding tasks. Research has shown that both require that L2 students have a good grasp of the source material not only in terms of understanding, analyzing, synthesizing, and evaluating the information found in the sources (the cognitive aspects of reading and writing), but also in terms of selecting information, organizing, drafting, and revising their papers which are the metacognitive aspects of the said complex writing activities (Campbell, 1990; McDonough, Crawford, \& De Vleeschauwer, 2014; Murray, Parrish, \& Salvatorri, 1998; Nambiar, 2007, in Lin \& Maarof, 2013).

Two of the most important reading and writing skills that may help L2 students demonstrate their telling and transforming knowledge are paraphrasing and summarizing. Although several studies have identified students' difficulties when utilizing paraphrasing and summarizing, there is a need to further investigate this area from the students' perspective as previous studies from this angle is quite scarce. In this paper, a qualitative study of the reflective essays written by 120 freshman undergraduate students from a private

\footnotetext{
* Corresponding Author

Email: eden.flores@dlsu.edu.ph
} 
university in Manila was conducted to determine their reported difficulties when they were asked to paraphrase and to summarize reading materials in preparation for their essay writing tasks. This paper not only looked at the challenges they face when doing so, but it attempted to determine the skills they think they need to improve on, their take on how they can help themselves deal with the writing tasks and the assistance their peers and teachers can extend to them to improve their summarizing and paraphrasing skills.

Summarizing and paraphrasing are both reading and writing skills which require L2 students to understand and express in their own words, ideas from source materials which they should also acknowledge or cite. In their study, Hirvela and Du (2013) have stated that while a summary (which can contain a paraphrase, but not confined to it) is a significantly condensed version of a longer original text achieved by capturing in the writers' own words its key information in (an) entirely new sentence(s), a paraphrase is a "recast of individual sentences, creating a combination of original language and grammatical structures from the source text with some new words and grammatical structures" (p. 88). Hence, in principle, a summary is prescribed to be no longer than one-third of the original text; a paraphrase may be as long as its source text or, when necessary, can be longer to "allow the writer to retain the same level of specificity as the original source text" (Hirvela \& Du, 2013, p. 88).

Summary writing, as a stand-alone task (Kim, 2001, in Wette, 2010), requires that students should first be able to read and fully understand the source text before they can decide which details to include, omit, or condense when they write a summary or gist of the source texts. This decision-making processes in summary-writing can best be facilitated by two of the essential reading skills: ability to identify between the main and minor ideas in a source text, as well as the reading comprehension skill to distinguish between relevant and irrelevant details. Corollary to this, understanding the linguistic or grammatical structures and discourse strategies employed by the text author may allow L2 students to manipulate or to restructure these patterns, or in the case of vocabulary, replace them to make the text accessible to readers. As has argued (Baba, 2009), good summaries demonstrate the students' mastery of manipulating sentence structures and vocabulary replacements to express in their own words the text author's main points and original meaning. The quality of the summaries and paraphrases they produce depends very much on how well they understand the source text. However, such mastery can only be utilized or demonstrated after L2 students have unearthed and unpacked the meaning of the information found in the source text. Abasi and Akbari (2008, in McDonough et al., 2014) have proposed that summary writing can be tapped as a means of assessing students' comprehension skills for it "may encourage students to reproduce source text information closely as a form of knowledge display rather than mere selectively appropriate main ideas and reasons" (p. 21).

Similarly, writing substantial paraphrases also demand that students have a full grasp and understanding of the source text before they can demonstrate their ability to "recast the passage into a freely formed version of the original" without compromising the essential meaning of the source (D'Angelo, 1979, p. 256). This ability to state the writer's ideas in their own words include only general words related to the topic that repeatedly appear in the source text (Keck, 2006). Conversely, superficial paraphrases (Keck, 2010; Roig, 1999, in Shi, 2012), or patchwriting (Howard, 1995) are characterized by minor modifications as shown in the L2 writers' use of word substitutions, deletions, or rearrangements of sentence structures from the source text. Keck (2014) has argued that this could be attributed to L2 students' lack of the ability to understand the key ideas and to linguistically alter these words in their paraphrases, while Abasi and Akbari (2008) have claimed that many L2 students take the risk of superficial paraphrasing because of a lack of confidence in rephrasing source texts in their own words.

However, it can be argued that a good paraphrase does not only mean or show substantial modifications of the original text and giving credit to the original author (Shi, 2012). After analyzing exemplary paraphrases on some North American college websites on plagiarism, Yamada (2003) argued that a good paraphrasing also demands inferential thinking, which could either lead to arriving at a conclusion based on statements or premises (deductive inferencing) or to noticing similarities between two domains (analogical inferencing). The idea of restating the original text to combine source information with one's own thinking, as Yamada (2003) has pointed out (1) contradicts how students are instructed to paraphrase and present a faithful account of the source text, and (2) signals the mastery of good paraphrasing and academic literacy that distinguishes experienced writers from novice writers. In the same vein, Keck (2010) has observed that substantial paraphrases in student writing are achieved not only by transforming the major components in original excerpt (subject, verb, and object) into different grammatical forms to express the same idea (clause element revision), but also by adding a phrase or clause to convey ideas that are not explicitly mentioned in the original text (clause element creation). However, apart from Yamada and Keck, there has been little effort to clarify how incorporating one's point of view into a paraphrase is accomplished.

Exactly what function does summarizing and paraphrasing serve in an academic writing? As mentioned earlier, both skills demonstrate the students' abilities to understand and articulate what they read, and to develop their own arguments or assertions by incorporating pertinent ideas from the source texts (Campbell, 1998). Previous studies have shown that students' effective summarizing and paraphrasing skills 
correlate with their academic success (Kirkland, \& Saunders, 1991), increased inferential thinking (Yamada, 20013, in Shi, 2012), promotion of their dialectical thinking (Bean, 1986, in Hirvela \& Du, 2013), and "explicitly referenced source texts with significant changes in the occurrence of copied and modified word strings" (McDonough et al., 2014, p. 20). Though, given the importance and relevance of these skills in language learning, summarizing and paraphrasing especially in academic contexts prove to be two of the most difficult-to-master skills (see, for example, Lin \& Maarof, 2013; Shi, 2012).

Summary writing skills of both low- and highproficient writers were compared by Johns and Mayers (1990, in Hirvela \& Du, 2013) and their study revealed that both groups found summarizing to be difficult as they "struggled to condense content from longer texts" (p. 89). Campbell (1990) likewise compared undergraduate students whose first language is English (L1 learners) and students who learned it as a second language (L2 learners) in terms of their ability to use source texts in their writing. Results revealed that both groups relied less on the source texts and used more of their own words in the body paragraphs of their papers; however, they heavily relied on the source texts in their conclusions. In addition, native speakers of English in the group, compared to L2 learners, minimally relied on source texts in their introductory paragraphs.

Furthermore, among L2 learners, other studies that examined students' writing outputs identified some notable and relevant weaknesses in their summarizing and paraphrasing performance: direct copying of sentences from source texts (Keck, 2006; Shi, 2004), combining of sentences from source texts using incorrect conjunction words (Idris, Baba, \& Abdullah, 2009), inability to differentiate between main ideas and supporting details (Othman, 2009, in Lin \& Maarof, 2013), and failure to capture the main ideas of the source text in the beginning sentence of their summary (Macbeth, 2006, 2010). Studies have been conducted with regard to the challenges L2 student writers deal with in demonstrating their knowledge telling and knowledge transforming in their paraphrase outputs (Hirvela \& Du, 2013; Shi, 2012), as well as on how explicit instruction over a period of time can improve summarizing and paraphrasing performance (Chen \& Su, 2012; Choy \& Lee, 2012; Wichadee, 2010; Wette, 2010).

Noteworthy here is Sun's (2009) study, where graduate students were asked to identify acceptable and unacceptable paraphrasing strategies. Results revealed that more than $50 \%$ of the respondents considered "keeping the source as intact as possible while making some mechanical changes such as reordering, using synonyms, and inserting is more acceptable than making syntactic changes and combining" (p. 402). The author has explained that this perception could be attributed to the students' lack of understanding about the potential risks of language plagiarism and concluded that this is indicative of participants' inadequate preparation for the graduate school scholarly writing requirements.

Interestingly, Messer (1997, in Lin \& Maarof, 2013) has claimed that summarizing skills has largely focused on the reading component to the neglect of the writing skills. He further argued that equal attention be given to both the reading and writing components when researching on learners' summarizing skills.

In essence, previous studies have revealed that summarizing and paraphrasing are important as well as problematic for both L1 and L2 learners. What is yet to be answered is why it is so problematic for student writers. Most researchers focused on comparing texts produced by different groups of students (e.g., L1 vs. L2; low- vs high-proficient) and on identifying the weaknesses in their written works (e.g., verbatim copying; lack of clear understanding of the source texts, lack of preparation, etc.). Little is known, however, as to why L2 students find it difficult when they are asked to summarize and paraphrase and what will aid them in effectively performing the tasks.

In order to shed light on this aspect of academic writing from the students' perspective, and to contribute to the on-going discussion on its pedagogical implications, this study sought to determine the reported difficulties L2 students have in summarizing and paraphrasing and what they think would help them improve their skills. Specifically, it attempts to answer the following two questions:

1. What difficulties do L2 students have in summarizing and paraphrasing?

2. How can L2 students improve their summarizing and paraphrasing skills?

\section{METHOD \\ Participants}

The randomly selected participants were 120 Filipino undergraduate students $(\mathrm{M}=60 ; \mathrm{F}=60)$, aged 16-18 years old, at a large, private university in Manila who were taking a required English language course. Of the 120 participants, 19 were pursuing a degree in the humanities, 41 in business and economics, 20 in computer science, 18 in engineering, and 22 in education. All claimed to have studied English for six to13 years either in private or public schools across the country. All passed the university's admission tests and their English proficiency based on CEFR level is C1Effective operational proficiency.

\section{Instructional contexts}

The English language course used in this study is designed to develop students' critical thinking skills in reading and writing, which include summarizing and paraphrasing as basic reading and writing skills. At least two meetings are allotted for explicit instructions, practice exercises and quizzes for the discussion of the said skills. Per University policy, the class size is limited to 25 students which meet four times in a week for 90 minutes per session over a 14-week trimester. 
There are no prescribed textbooks for the course but teachers are free and expected to prepare and use a variety of instructional materials appropriate to their students' reading levels in order to meet the course's reading-into-writing requirements.

At the end of the term, students should have written two 5-themed papers (also called major papers); namely, an extended definition essay, and an argumentation paper. In preparation for writing these major papers, students are also required to write at least three 3-themed papers (considered minor papers) that include a descriptive essay, a cause-effect essay, and a comparison-contrast essay.

The Department subscribes to the principles of process approach to writing, and students are expected to brainstorm, gather information, outline, write the first draft, peer edit, revise, proofread, before writing their final drafts. Given this, a writing task would usually take a week or two before the students would be asked to submit their final drafts. Student-teacher conferencing is also observed to guide students in their various writing stages. It is important to note here that only the final drafts are graded in compliance with the principles of the said writing approach. Students are expected to use various rhetorical patterns especially in their major papers and are required to incorporate ideas or information from at least five source texts. Rubrics approved by the Committee are used in assessing each writing output. The use of the latest edition of APA documentation style is strictly enforced. In lieu of a final written examination, students submit a digitized portfolio - a showcase of their best writing outputs which is graded based on a set of rubrics specific to this output/requirement.

\section{Data analysis/coding}

After their lessons on summarizing and paraphrasing source texts, for the purposes of this particular study, students were asked to reflect on the following points: their difficulties regarding these skills, and what they can do to address these difficulties. Guide questions were provided but they were not limited nor forced to use them in accomplishing the task (see Appendix A for a copy of these guide questions.). They were instructed to email their reflection papers in Word format to their teachers and to express in writing their consent for the inclusion of their papers for this study. No extra course credits nor any other forms of remunerations were given to the students who expressed voluntary participation in this project. Students' papers were assigned codes (e.g., $\mathrm{S} 1, \mathrm{~S} 2, \mathrm{~S} 3$, etc.) for anonymity.

Table 1. Coding categories with examples

\begin{tabular}{ll}
\hline Types of difficulty & Student examples \\
\hline Vocabulary & "I don't know what the correct word to use." \\
$\begin{array}{l}\text { Usage } \\
\text { Synonyms/Antonyms } \\
\text { Word formation }\end{array}$ & "I don't know a word with similar meaning." \\
& and vice-versa"
\end{tabular}

\section{Reading comprehension Identifying topic/main ideas}

Identifying support details

Inferencing/Making conclusions

Language proficiency

Grammar/Sentence construction

Expressing/Organizing ideas in own words
"I have problems identifying the main idea of the text."

"I didn't know which details to include and I might omit important details or include details that aren't needed."

"I don't get the main idea if it's not stated in the selection."

"I have problems organizing my thoughts."

"I don't know how to restate the author's ideas in my own words."

"I don't know how to cite sources."

Documentation skills

discrepancies in coding were mainly brought about by nuances in understanding the descriptors and definitions (and sometimes overlapping characteristics) of (sub)themes which were easily addressed when the authors went over the problematic items of the data. Where these discrepancies occurred, they were resolved by going back to the nature of each type and sub-type. These were then tabulated in Excel file/worksheet and descriptive statistics (frequencies and percentages) was used to analyze participants' responses. Sample statements from the data were provided to illustrate each type. 
FINDINGS AND DISCUSSION

What difficulties do L2 students have in summarizing and paraphrasing?

In the first coding of the general difficulties reported in the reflection essays of the participants, students attributed their difficulties in summarizing and paraphrasing to their lack of English proficiency (99\%), poor reading comprehension skills $(88 \%)$, lack of vocabulary $(60 \%)$, insufficient knowledge or lack of documentation skills $(50 \%)$ and other related reasons $(13 \%)$. In re-examining the data, more specific difficulties (sub-types) under each general type surfaced. These difficulties vary from lack of focus $(0.83 \%)$ to lack of vocabulary $(38 \%)$. Table 2 summarizes the general and specific types of difficulty students reported in performing the writing skills with their frequency and percentage distribution.

As can be seen in Table 2, when grouped according to general types of difficulty, students' identified difficulties in summarizing and paraphrasing indicate that lack of English proficiency (99\%) is their number one difficulty. This noted lack of confidence in their language skills was also identified in previous studies involving students' success in collaborative writing in the classroom (Lin \& Maarof, 2013), smooth collaboration and writing (Yong, 2006), and engagement in collaborative writing (Storch, 2005). Kirkland and Saunders (1991) have likewise identified L2 proficiency as one of the factors affecting successful writing performance, particularly, in summary writing. When broken into more specific themes, restating the source text's ideas into one's own words $(n=37,31 \%)$ is the most common difficulty identified by the students. These language-related concerns among the respondents are evidenced by students' responses. "Creating an entirely different sentence without losing the thought/impact of the original sentence" (S3) and "trying to reword the sentence into an entirely new one" (S6) as reported by the students in this study echo this language-related concern among L2 learners. What is interesting, however, is the fact that despite the students' reported number of years of learning English (that is, six to 13 years) and their English proficiency level equivalent to CEFR C1- Effective operational proficiency, the participants in this study are still not that confident in their ability to use the language. Bean (1986, in Lin \& Maarof, 2013) suggested that it is not surprising that L2 learners struggle with writing tasks, like summarizing and paraphrasing, that would require articulating ideas not their own.

Table 2. Frequency and percentage distribution of students' reported difficulties in summarizing and paraphrasing $(\mathrm{N}=120)$

\begin{tabular}{lrr}
\hline \multicolumn{1}{c}{ Difficulty } & f & \multicolumn{1}{c}{$\%$} \\
\hline Lack of English proficiency & 119 & 99.17 \\
Restating source ideas into own words & 37 & 30.83 \\
Observing length/content requirements of a summary/paraphrase & 34 & 28.33 \\
Composing grammatical sentences & 26 & 21.67 \\
Restructuring sentences & 11 & 9.1 \\
Organizing thoughts & 11 & 9.1 \\
& & \\
Poor reading comprehension skills & 105 & 87.50 \\
Identifying the topic sentence/main ideas & 33 & 27.50 \\
Understanding/interpreting the source text & 31 & 25.83 \\
Selecting/deleting/overlooking supporting details & 30 & 25.00 \\
Organizing/classifying details & 8 & 6.67 \\
Lacking reading skills & 3 & 2.50 \\
& & \\
Lack of vocabulary & 72 & 60.00 \\
Lacking vocabulary & 46 & 38.33 \\
Using synonyms to replace words in the source texts & 21 & 17.5 \\
Changing word forms & 5 & 4.17 \\
& & \\
Poor/lack of documentation skills & 60 & 50.00 \\
Lacking knowledge in citing sources & 40 & 33.33 \\
Misinformation about documentation & 18 & 15.00 \\
Fear of plagiarism & 2 & 1.67 \\
& & \\
Others & 16 & 13.33 \\
Time constraint/Pressure in performing the task & 7 & 5.83 \\
Lack of practice & 3 & 2.50 \\
Attitude towards the skills & 2 & 1.67 \\
Fear of making mistakes & 1 & 0.83 \\
Lack of focus & 1 & 0.83 \\
\hline
\end{tabular}

Arguably, this lack of confidence among the participants may also be due to the rigid requirement of observing length/content requirements of a summary/paraphrase $(\mathrm{n}=34,28 \%)$, reported as the second highest reported difficulty under the general theme, lack of English proficiency. It has been 
established that summarizing and paraphrasing are cognitively demanding writing skills on the grounds that students are not only required to fully understand the source text, but they also need to reconceptualize the source ideas by moving from "the specific and local to the general or macro" (Nambiar, 2007, in Lin \& Maarof, 2013, p. 600). Strict compliance with the explicit instruction/requirement found in various writing textbooks observed that summaries should not be longer than one-third of the original text and this could have posed additional difficulty for the students in completing the writing tasks. In essence, a combination of these demands may prove to be daunting for L2 students since they are not only concerned with clarity of their reconceptualization of someone else's ideas, but also their need to be concise as well, while retaining the original meaning and emphasis of the source text.

Poor comprehension reading skills $(\mathrm{n}=105,88 \%)$ as a general type of difficulty prefigures as the second highest source of difficulty reported by the students in their reflection papers. The problems of understanding information from a source text with regard to its topic, main idea, and support details prove to be challenging to these students. The same problems are encountered by university students in Wette's study (2010) as findings indicate that they "had difficulties at times with extracting core or specific meaning from complex source texts and with processing that understanding to compose appropriate paraphrase or summary citations, in selecting relevant and citation-worthy text extracts, understanding the propositional content of texts, among others (Wette, 2010, p, 168). Other manifestations of poor reading skills as reported in other studies include inabilities to be critical of the text contents (e.g., Shi, 2004) and not clearly distinguishing between primary and secondary citations (Pecorari, 2003). Poor reading skills have also been identified by Esmaeili (2002) and Plakans (2009) as the cause of students' verbatim copying of source text in their written outputs. They further suggested that the non-use of modification strategies (i.e., the use of synonyms or the restructuring of words in a string of words copied from the source text) in their summaries is an indicator of the students' inability to comprehend the texts. Howard (2001, in Hirvela \& Du, 2013) has also argued that "flawed attempts at patchwriting/ paraphrasing and summarizing may also result from struggles with reading" (p. 89). Commonsensically, the students' ability to understand the source well have a direct influence on how well they will write for they need to first understand the source text well before they can select relevant information worth citing or including in their summaries or paraphrases. The quality of the text they produce depends very much on the quality of that comprehension.

A closer look at Table 2 would also reveal that the sub-theme lacking vocabulary $(\mathrm{n}=46,38 \%)$ compared to restating source ideas into own words $(n=37,31 \%)$ is reported to pose more difficulty among students when they were asked to summarize and paraphrase source texts. Responses such as, "Thinking of a word to replace or the synonym of a certain word" when paraphrasing "was very hard" (S13), while "regrouping the words in one general category" when summarizing "was difficult for me" (S15) are reminiscent of previous studies (see, for example, Chen \& Su, 2012; Choy \& Lee, 2012) where concerns about inadequate vocabulary and grammar development when writing summaries have been reported. It has been established by several studies that difficulties in writing may be traced back to their poor reading skills (e.g., Keck, 2014; Howard, 2001, in Hirvela \& Du, 2013; Wette, 2010). Worth quoting here is one student's admission that $\mathrm{s} /$ he may "improve my vocabulary by being a wide reader" (S11). However, in light of the students' reported difficulties, and in particular, the sub-theme, using synonyms to replace words in the source texts $(n=21,18 \%)$, it could be safe to assume here that some of them think that summarizing and paraphrasing would only entail checking the thesaurus and looking for words that they can use to substitute or replace a word in the text. Practices like these often result in choosing words that are often fancy and usually inappropriate since L2 learners have the notion that big words usually would impress their teachers or readers. Unfortunately, they don't realize that mere word substitutions or switching words around is a superficial way of paraphrasing (Keck, 2006). "It is essential for teachers to emphasize that summarizing and paraphrasing is a transition from knowledge-telling to knowledge-transforming, and they should not assume that teaching word replacement and grammatical restructuring strategies is all that paraphrasing instruction is about" (Hirvela \& Du, 2013, p. 97).

Another specific type of difficulty that students reported facing when summarizing and paraphrasing is their lack of knowledge in citing or documenting their sources $(n=40,33 \%)$. Interestingly, some claimed that they were misinformed about the proper way of doing it $(\mathrm{n}=18,15 \%)$. Moreover, they thought that acknowledging the sources is unnecessary since they used their own words in incorporating into their own writings, ideas from source materials. This difficulty likewise prefigured in other studies where issues connected to plagiarism were examined (see, for example, Macbeth, 2010; Pecorari, 2008; Shi, 2010). From a more recent educational standpoint, however, a different way of looking at plagiarism has evolved and rather than looking at it as a transgressive act, patchwriting, or textual borrowing (see Pennycook, 1996; Howard, 1999, and Belcher \& Hirvela, 2001), experts now (e.g., Abasi \& Akbari, 2008; Harwood \& Hadley, 2004; Howard, 2001 Pecorari, 2003, 2008b) have argued that "unacknowledged copying and patchwriting are much more likely to stem from developmental needs than from deliberate dishonesty, and that writing using sources is a complex, learned literacy for both L1 and L2 writers" (Wette, 2010, p. 160). Given the limited vocabulary they have at their disposal, coupled with their inability to express in their 
own words, ideas found in the source text, it is not surprising that students would resort to copy-paste mode when asked to include information from source texts in their written outputs. It could also be attributed to the fact that the kind of writing these freshman college students were exposed to in their high school days (which are mostly literary and creative writings) and were expected to produce (usually personal/reflective essays), where not much explicit instruction on how to properly document their writings was given since these types of writing would not require incorporating information from source texts to their own personal essays or creative writing outputs.

Lastly, although the number of instances is not so alarming, students nevertheless reported under time pressure $(n=7,6 \%)$ as one of their difficulties when summarizing and paraphrasing especially when the writing activities were done inside the classroom. The course, as stipulated in the syllabus, requires that all writing activities be done inside the classroom to ensure that the students are the ones that really write their essays. Noteworthy, too, is the fact that the students' attitude towards these writing skills $(n=2,2 \%)$ is also reported as a hindrance to an effective summarizing and paraphrasing performance. Previous studies point to the fact that the learners' attitude towards cognitively demanding tasks play a role in how successful they would be in performing the said tasks.

\section{How can L2 students improve their summarizing and paraphrasing skills?}

After determining the types of difficulty students faced in summarizing and paraphrasing as reported in their reflection papers, the authors then determined how these difficulties could be addressed or improved on, again from the students' perspective. Table 3 presents a summary of these strategies as identified by the students in their reflection papers.

Table 3. Students' strategies to address reported summarizing and paraphrasing difficulties

\begin{tabular}{ll}
\hline Type of difficulty & Strategies \\
\hline Lack of English proficiency & Improve sentence writing \\
Improve knowledge of grammar & Know different sentence structures \\
& Practice more through homework/reports \\
Write one-sentence summary per paragraph & Improve ability to restate in one's own words ideas from source materials \\
& Identify writer's voice \\
Poor reading skills & Read more/various types of materials \\
& Read texts several times \\
& Rank ideas \\
Take notes \\
Make inferences \\
Get the feel of the gist \\
Activate prior knowledge \\
Increase/widen vocabulary \\
Use synonyms \\
Know appropriate reporting verbs \\
Use hedging devices \\
Preofread one's work \\
Pocabulary \\
Review APA or required documentation style \\
Follow documentation guidelines \\
\\
Follow exemplar works \\
Attend tutorials offered by school \\
Allot more time to complete task \\
Stay awake/listen/participate in class \\
Pray \\
\hline
\end{tabular}

It is interesting to note that the students in this study have a very good grasp of how they can address their summarizing and paraphrasing difficulties based on the strategies identified and enumerated in their reflection papers. Although these strategies are very general and broad in nature, noteworthy is the fact that for each difficulty they encounter, they identified specific strategies to address it. For example, they reported that "writing a one-sentence summary per paragraph" may, in particular, address their lack of proficiency in the English language. Likewise, in order to address their inability to restate source ideas into own words, "knowing the different sentence structures" as a strategy, might do the trick. In Dovey's study (2010), for example, drawing from the work of socio-cognitive process theorists such as Spivey (1990) and Kucer (1985), the tasks and teaching activities oriented towards genre-based instruction were revised to allow 
for a focus on the processes of organizing, selecting, and integrating information from multiple sources that enable writing from sources. Accordingly, this allows novice writers in a field to have greater control over the transformation and construction of meaning as they move backwards and forwards between source texts and their own emerging text. The study has claimed that these changes have resulted in an improvement in the organization, coherence and cohesion of the final document, as well as a reduced incidence of patchwriting.

As for their poor reading skills, students in this study enumerated several ways to improve their reading comprehension skills: 1) Read more/various types of materials; 2) Read texts several times; 3) Rank ideas; 4) Take notes; and 5) Make inferences. These suggested strategies are concurred by several studies aimed at determining the impact of reading into writing processes. For example, making notes while reading tended to gain students a literal understanding of the topic (Stahl, Hynd, Britton, McNish, \& Bosquet, 1996, in McCulloch (2013), greater levels of inferencing when reading helped L2 university students to write better summaries (Yamada, 2002), and those who set reading goals, used self-monitoring strategies and identified main ideas while reading produced higher-scoring essays (Plakans, 2009, in McCulloch, 2013).

Interestingly, "Attend tutorials offered by school" as another way to improve their summarizing and paraphrasing skills indicates students' awareness of the support the school provides them. Students may voluntarily sign up in the free remedial sessions offered by the Department in its writing laboratory to help address reading and writing weaknesses of the students enrolled in the said English course. Teachers are, likewise, reminded to strongly encourage their students to avail of these services. Finally, the suggestion to "pray" to address their difficulty in summarizing and paraphrasing source texts could either be taken as a reflection of their desperation or a firm belief in practiced religion, the University being pre-dominantly Catholic in population.

\section{PEDAGOGICAL IMPLICATIONS AND INTERVENTIONS}

Several implications can be drawn from the results of this study. And these will further be divided into reading and writing instruction.

When $88 \%$ or a total of 105 out of 120 students who participated in this project admitted to having poor reading comprehension, evidently, there is a need for relevant reading instructions. Following the lead reported by the students in their reflection papers, it is imperative that such instruction be explicit enough to focus on the development of reading comprehension skills as basic as identifying the topic sentence, main ideas, understanding and interpreting the source text, and selecting/deleting/overlooking supporting details. It is commonsensical to argue that before they can incorporate into their own writings, information from a source texts, they need to first, be able to determine the topic of the text, to identify the author's main idea, and to evaluate whether certain details found in there are relevant or not. It will be unfair to the learners, if not an exercise in futility, to expect them to summarize and paraphrase a source text when they do not understand it. Several studies and ample evidence in various contexts have reported how direct instruction develops the reading skills of students (see, for example, Brown \& Dale, 1983; Cumming, et al. 2018; Dovey, 2010). Corollary to providing explicit instruction to L2 learners is holding review lessons and giving exercises on basic reading skills, such as identifying the topic, the main idea and the supporting details of a text which may help teachers diagnose their students' ability to comprehend a text. Based on the results of these (diagnostic, or otherwise) exercises, instruction may then progress from teaching basic to advanced reading skills, from comprehending simple texts to reading materials that will also require them to infer, draw conclusions, and evaluate not only the author's intent but the text's content as well. It is suggested that teachers model the reading processes to provide students some insights on how adults grapple with texts. It might also be a good idea to provide tutorials and a lot of exercises for those with low English proficiency levels. As previously mentioned, the university where this project was conducted provides free remedial reading and writing lessons to students who might need them. Improved reading skills have been noted among students who availed themselves for these additional reading sessions. In the absence of a reading-writing laboratory, teachers may spend some time with their students outside class hours to address these reading deficiencies or provide some practice exercises that they can do at home.

Ninety-nine per cent of the participants in this study attributed their difficulty in summarizing and paraphrasing to lack of English proficiency $(n=119)$ which include inabilities to restate source ideas into own words, observe length/content requirements of a summary/paraphrase, compose grammatical sentences, restructure sentences and organize thoughts. In terms of writing instruction and depending on the students' English proficiency level, utilizing genre-based approach where explicit instruction on various text types and their distinguishing features and organizational structure may help acquaint students identify the parts of a text. Research has shown positive correlation between explicit instruction concerning organizational structures of texts and students' writing outputs (Kirkpatrick \& Klein, 2009, in McDonough, et al., 2014). Familiarity with how writers organize their ideas may provide some assistance or guidelines for students to present or organize their own ideas. Summarizing and paraphrasing these texts may likewise start with a one-sentence summary or paraphrase and gradually increase to paragraph- and discourse-level written outputs. Furthermore, adaptation of a processbased approach where students experience 
brainstorming, outlining, writing, "often enhanced by responding, evaluating, and post-writing" (Seow, 2002, in Romova \& Andrew, 2011, p. 112) has opened the way to view writing as a transactional activity. Several researchers have pointed out that both genre-based and process-based approaches to writing have proved to be beneficial to novice writers, despite their intrinsic limitations and contradictions with each other (Cheng, 2006; Romova \& Andrew, 2011; Swales, 2004, in Dovey, 2010). In exploring the role of process-oriented approach vis-à-vis genre-based pedagogies in facilitating writing from sources of her postgraduate students, Dovey (2010) has this conclusion: The recursive processes of of organizing, selecting, and integrating information that focus on the generation and transformation of meaning in specific communicative contexts do not contradict the principles of genre-based approaches. She has further argued that in light of this drawn conclusion, "the notion of process be recuperated, and that the management of processes be taught in tandem with genre awareness to address the full range of students' reading-writing needs" (p. 45). Teachers must be aware, however, that instruction is needed at different stages with different text types for the optimal development of their students' writing skills.

Equally important at this stage is the need to emphasize that writing need not always be solitary nor performed individually at all times. Vygotsky's Zone of Proximal Development (ZPD) has informed the way writing is taught where assistance may take the form of teacher/student interaction, or peer tutoring, or group activity (Brindley, 2005) and where "group members use mediational means collaboratively to create, obtain, and communicate meaning" (Moll, 1989, in Lin \& Maarof, 2013, p 601). Ample evidence exists to show how collaborative writing has helped improved L2 learners' overall writing performance. Storch (2005), for example, has found that students produce more grammatically accurate and more linguistically complex papers. At the same time, "learning to write is part of becoming socialized to the academic community finding out what is expected and trying to approximate it" (Silva, 1990, in Romova \& Andrew, 2011, p.113).

\section{CONCLUSION}

Students' success in summary and paraphrase writing is dependent on various skills. First, in the list is the ability to express oneself in the target language, which in the context of this study, is English. The ability to understand the contents of the source text comes second. Thirdly, a broad range of vocabulary is a big help for students to express in their own words, ideas found in the source texts. These three inter-woven reading-into-writing skills are at the core of the summarizing and paraphrasing difficulties 120 freshman students from a private university in Manila reported in their reflection papers after a series of discussion on the said topics. Some researchers, (e.g., McDonough, et al.,
2014; Shi, 2004) have argued that these writing outputs may not be appropriate writing tasks for L2 learners whose proficiency in the target language is low given the cognitive demands summarizing and paraphrasing have on the students. However, a quick look at the language textbooks sold in commercial book stores found in Manila would indicate that as early as elementary grades, these learners are expected to learn and show mastery of summarizing and paraphrasing skills. How then can this problem be addressed? On the one hand, there is a need for the students to acquire these skills as early as possible only to facilitate understanding of and appreciation for ideas found in written texts. On the other hand, given the cognitive load of knowledge telling and knowledge transforming (Bereiter \& Scardamalia, 1987) inherent in summarizing and paraphrasing, it may be ambitious, if not unfair, to demand L2 learners lacking language proficiency to exhibit mastery in these areas.

Firstly, it might be good to revisit the roles these writing skills play in the academic life of university students. Instead of looking at these writing outputs as indicators of their success in college, program developers and educators may view these as indicative of their constant struggle to make sense of the written world. As McDonough, et al. (2014) have argued, the whole issue of summary and paraphrase writing can be viewed and appreciated through "reference to the conceptualization of L2 writing as a learning-to-write or writing-to-learn schema" (p. 29), where students learnto-write to assimilate and become active members of a speech community as opposed to write-to-learn students whose goal is to practice and learn the target language, whatever it may be. As evidenced in Hirvela and Du's study (2013), students need to be oriented well towards the role and real value summarizing and paraphrasing have in their lives. The authors have argued that greater emphasis must be given to the purposes of these skills and how they could be valuable tools for transforming knowledge, not simply an escape to avoid plagiarism. Secondly, given the numbers of students who reported lack of proficiency in the English language and poor reading comprehension skills as sources of their difficulties, further research into how L2 learners can best benefit from what type of instruction, both inside and outside classroom settings is in order. If research has shown that patchwriting is an indicator of L2 learners' struggle (Wen, 2016, in Cumming, et al., 2018) with summarizing and paraphrasing tasks, how can this be used as a tool to achieve linguistic and reading literacies among them? What reading exercises and writing tasks would lead them towards acquisition of the target language and automaticity in using formulaic expressions and employing generic styles prevalent in the discourse community they intend to be members of? Finally, summarizing and paraphrasing writing tasks could be powerful avenues to train L2 learners to collaborate with fellow learners as they grapple with the text, make sense of what they read, create their own ideas, revise, reflect, and transform 
knowledge into a new one - in essence, what summarizing and paraphrasing is all about. After all, the end goal of college education is to prepare learners to become active and productive members of the community or industry they plan to be part of.

\section{REFERENCES}

Abasi, A. R., \& Akbari, N. (2008). Are we encouraging patchwriting? Reconsidering the role of the pedagogical context in ESL student writers' transgressive intertextuality. English for Specific Purposes, 27(3), 267-284. doi: 10.1016/j.esp.2008.02.001

Bereiter, C., \& Scardamalia, M. (1987). The psychology of written composition. Hillsdale, NJ: Lawrence Erlbaum.

Brindley, S. (Ed.). (2005). Teaching English. London: Routledge.

Brown, A. L., \& Day, J. D. (1983). Macrorules for summarizing texts: The development of expertise. Journal of Verbal Learning and Verbal Behavior, 22(1), 1-14. doi: 10.1016/S0022-5371(83)80002-4

Campbell, C. (1990). Writing with others' words: Using background reading text in academic compositions. In B. Kroll (Ed.). Second language writing (pp. 211-230). Cambridge: Cambridge University Press.

Campbell, C. (1998). Teaching second language writing: Interacting with text. Boston: Heinle \& Heinle.

Chen, Y., \& Su, S. (2012). A genre-based approach to teaching EFL summary writing. ELT Journal, 66 (2), 184-192. doi: doi.org/10.1093/elt/ccr061

Choy, S., \& Lee, M. (2012). Effects of teaching paraphrasing skills to students learning summary writing in ESL. Journal of Teaching and Learning, 8(2), 77-89. doi: 10.22329/jtl.v8i2.3145

Cumming, A. Yang, L., Qiu, C., Zhang, L. Ji, X., Wang, J., ... \& Lai, C.(2018). Students' practices and abilities for writing from sources in English at universities in China. Journal of Second Language Writing, 39, 1-15. doi: 10.1016/j.jslw.2017.11.001

D’Angelo, F. J. (1979). The art of paraphrase. College Composition and Communication, 30, 255-259.

Dovey, T. (2010). Facilitating writing from sources: A focus on both process and product. Journal of English for Academic Purposes, 9(1), 45-60. doi: 10.1016/j.jeap.2009.11.005

Esmaeili, H. (2002). Integrating reading and writing tasks and ESL students' reading and writing performance in an English language test. Canadian Modern Language Review, 58(4), 599-622. doi: 10.3138/cmlr.58.4.599

Hirvela, A., \& Du, Q. (2013). "Why am I paraphrasing?": Undergraduate ESL writers' engagement with source-based academic writing and reading. Journal of English for Academic Purposes, 12(2), 87-98. doi: 10.1016/j.jeap.2012.11.005
Howard, R. M. (1995). Plagiarisms, authorships, and the academic death penalty. College English, 57(7), 788-806. doi: 10.2307/378403

Howard, R. M. (2001, March). Plagiarism: what should a teacher do? Paper presented at the Conference on College Composition and Communication, Denver, Colorado.

Idris, N., Baba, S., \& Abdullah, R. (2007). An analysis on student-written summaries: a step towards developing an automated summarization assessment. Proceedings of the International Conference on Electrical Engineering and Informatics Institut Teknologi Bandung. Bandung, Indonesia: Institut Teknologi Bandung.

Johns, A., \& Mayes, P. (1990). An analysis of summary protocols of university ESL students. Applied Linguistics, 1(3), 253-271. doi: 10.1093/applin/11.3.253

Keck, C. (2010). How do university students attempt to avoid plagiarism? A grammatical analysis of undergraduate paraphrasing strategies. Writing \& Pedagogy, 2(2), 193-222. doi: 10.1558/wap.v2i2.193

Keck, C. (2006). The use of paraphrase in summary writing: A comparison of L1 and L2 writers. Journal of Second Language Writing, 15(4), 261278. doi: 10.1016/j.jslw.2006.09.006

Kirkland, M.R. \& Saunders, M.A.P. (1991). Maximizing student performance in summary writing: managing cognitive load. TESOL QUARTERLY, 25(l), 105-122. doi: $10.2307 / 3587030$

Kirkpatrick., L., \& Klein, P. (2009). Planning text structure as a way to improve students' writing from sources in compare-contrast genre. Learning and Instruction, 19(4), 309-321. doi: 10.1016/j.learninstruc.2008.06.001

Lin, O. P., \& Maarof, N. (2013). Collaborative writing in summary writing: Student perceptions. Social and Behavioral Sciences, 90, 599-606. doi: 10.1016/j.sbspro.2013.07.131

Macbeth, K. P. (2006). Diverse, unforeseen, and quaint difficulties: the sensible responses of novices learning to follow instructions in academic writing. Research in the Teaching of English, 41(2), 181207.

Macbeth, K. P. (2010). Deliberate false provisions: The use and usefulness of models in learning academic writing. Journal of Second Language Writing, 19(1), 33-48. doi: 10.1016/j.jslw.2009.08.002

McCulloch, S. (2013). Investigating the reading-to-write processes and source use of L2 postgraduate students in real-life academic tasks: An exploratory study. Journal of English for Academic Purposes, 12(2), 136-147. doi: 10.1016/j.jeap.2012.11.009

McDonough, K., Crawford, W. J., \& De Vleeschauwer, J. (2014). Summary writing in a Thai EFL university context. Journal of Second Language 
Writing, 24, 20-32. doi:

10.1016/j.jslw.2014.03.001

Murray, A., Parrish, J., \& Salvatori, M. (1998, April).

To rewrite the text, I am reading: pedagogies of quotation. Paper presented at the Conference on College Composition and Communication, Chicago, Illinois.

Othman, N. (2009). Teaching and assessing three types of direct writing in Malaysian ESL classrooms - a survey of ESL teachers' opinions. English Language Journal, 3, 102-114.

Plakans, L. (2009). The role of reading strategies in integrated L2 writing tasks. Journal of English for Academic Purposes, 8(4), 252-266. doi: 0.1016/j.jeap.2009.05.001

Pecorari, D. (2008). Academic writing and plagiarism. London: Continuum.

Romova, Z., \& Andrew, M. (2011). Teaching and assessing academic writing via the portfolio: Benefits for learners of English as an additional language. Assessing Writing, 16(2), 111-122. doi: 10.1016/j.asw.2011.02.005

Shi, L. (2004). Textual borrowing in second language writing. Written Communication, 21(2), 171-200. doi: $10.1177 / 0741088303262846$

Shi, L. (2012). Rewriting and paraphrasing source texts in second language writing. Journal of Second
Language Writing, 21(2), 134-148. doi: 10.1016/j.jslw.2012.03.003

Storch, N. (2005). Collaborative writing: product, process, and students' reflections. Journal of Second Language Writing, 14 (3), 153-173. doi: 10.1016/j.jslw.2005.05.002

Sun, Y-C. (2009). Using a two-tier test in examining Taiwan graduate students' perspectives on paraphrasing strategies. Asia Pacific Educators Review, 10(3), 399-408. doi: 10.1007/s12564-0099035-y

Wette, R. (2010). Evaluating student learning in a university-level EAP unit on writing using sources. Journal of Second Language Writing, 19 (3), 158177. doi: 10.1016/j.jslw.2010.06.002

Wichadee, S. (2010). Using wikis to develop summary writing abilities of students in an EFL class. Journal of College Teaching \& Learning, 7(12), 510. doi: 10.19030/tlc.v7i12.951

Yamada, K. (2003). What prevents ESL/EFL writers from avoiding plagiarism? Analyses of 10 North American college websites. System, 31(2), 247258. doi: 10.1016/S0346-251X(03)00023-X

Yong, M.F. (2006). The nature and dynamics of collaborative writing in a Malaysian tertiary ESL setting (Unpublished doctoral thesis). Massey University, New Zealand.

\section{APPENDIX}

Guide Questions for Reflection Paper on paraphrasing and summarizing

Please reflect on your experiences, thoughts, insights, or feelings regarding our lessons on summarizing and paraphrasing. You may use the guide questions below when you write your reflection paper; but, remember that you are not limited to them.

1. What difficulties did you encounter when you were asked to paraphrase and summarize texts? Why?

2. How can you address these difficulties? How can you improve your paraphrasing and summarizing skills? 